\title{
The Emerging Social Work techniques in Youth Empowerment programs: A case Study of Youth Empowerment Organizations in Nairobi County.
}

\section{Edwine Jeremiah Otieno, Timothy Osiru Okatta, Wilkins Muhingi Ndege, Teresia Mutavi, Michael Tedd Okuku, Dr. Vitalis Okoth Odero, David Kimaili Mwendwa} \author{
St. Elizabeth University - Slovak,timothyokatta@gmail.com \\ St. Paul University, \\ University of Nairobi, \\ The Catholic University of Eastern Africa \\ Amoud University \\ South Eastern Kenya University
}

Tangaza University College (Constituent College of the Catholic University of Eastern Africa),

\begin{abstract}
Traditional techniques used in social work have become obsolete and ineffective in meeting the contemporary needs of the dynamic population. This has led to the development of new social work techniques that seek to achieve social transformation among the youth. These innovations which are being implemented by youth empowerment organizations are important not only to the social workers that utilize them and their clients but also for the upcoming professionals and institutions that provide services to the youth. The overall objective of this paper is to unravel the emerging innovative social work techniques applied by youth empowerment organizations that seek to achieve social transformation among the youth. This study is grounded on diffusion of innovation model and linear models of innovation. This study reviewed different articles related to social work techniques, social work methods, social work intervention books, youth empowerment programs, social innovations, and existing local and international literature using different material from related fields to get rich information. The reviewed literature revealed that there were new social work techniques that have emerged to address the needs of the contemporary and dynamic urban youth population. These innovations have neither been documented nor shared with other organizations and social work practitioners. Social workers also face challenges in developing new techniques and these contributes to poor outcomes with the concurrent diversity of the social problems. This study recommends documentation of emerging social work interventions in youth empowerment and development programs, sharing of information and utilization on the new techniques and methodologies among social workers working with the youth. Social workers need to be trained on how to utilize social research to enhance their capacity in technique development, and organizing regular seminars and workshops where social workers can share and learn more about the new and emerging social work interventions.
\end{abstract}

Key Words: Emerging techniques, Social Work interventions, youth, empowerment, development

\subsection{Background to the study}

The youths form almost half of the world's population with the majority under 25 years of age (Gribble, 2010). This population however is at a greater risk ranging from radicalization, terrorism, health among other maladjusted behaviour that put their life and that of the community at risk. The youth between ages 15 and 24 are in great need of social work interventions and only through the correct approach and methods can this be achieved (Gribble, 2010). Youth empowerment programs are key to addressing the contemporary youth recurrent challenges (Mutuku, 2011). Job creation, for economic empowerment has been in the heart 
of every nation globally with little attention on psychosocial empowerment. However, without inclusive intervention these efforts achieve little on empowerment of young people (James, Melanie, Erika, Jooyoung, \& Carrie, 2015).

Generally the youths are considered the future of the state since they determine its future development (Cohen, 2010). However, due to changes in the social institutions like the family and other factors like industrialization, urbanization, and environmental factors, the youth now face an ending and recurrent social problems in particular: health, unemployment, drug abuse, just to mention a few. (Gribble, 2010). Social workers have to deal with these new challenges in the society while directing their efforts towards conditions that degrade youth personalities, meeting basic needs, relationship enhancement, coping up with stress, personal attitude towards self and others (Dominelli, 2009).

Half of Africa population is made up of young people, these Africa's youth's live on less than \$2.00 a day (Mutuku, 2011). Besides earning low-income they are also faced with challenges hard to address, research shows that poor people die premature deaths, get married at a young age, and have large families, and experience malnutrition and ill health (Mwiti, 2006). In United States of America, the youths are dripping towards social isolation which has led to high growing body of epidemiology which include mental and physical health outcomes including mortality (WHO, 2008). James, Melanie, Erika, Jooyoung, \& Carrie (2015) noted that the disruption of personal ties, loneliness, and conflictual interactions produced stress among the young people in United States of America.

Young people in Africa are growing up in social environments where chances of living decent lives are negligible and with bleak prospects (Mutuku, 2011). These widespread challenges are "breeding", frustration, anxiety and despair, culminating in crime, drug addiction, and early pregnancy and alcoholism (Grace, 2016). Hopelessness and desperation has made young people easy recruits in armed rebel or insurgent movements experienced in some African countries today (Cramer, 2011). To address these social problems, Social workers are mandated to apply evidence-informed practices based on emerging research findings and empirical evidence to provide quality services to the young people (NASW, 2013).

The young population in Kenya constitute of 75 percent of the total population and it is estimated that this population is under the age of 35 years (Kahl, 2012). The Kenyan government has recognized that the youth have a role in shaping the country's social, economic and political development (Owuor, 2008). However, Kenya continues to experience a glaring mismatch between the aspirations of its youth and the opportunities available to them despite their high hopes and ambitions. (Agenda, 2013). This is clearly demonstrated by youth unemployment which is currently estimated to be over 70 percent in Kenya and a major concern to policy makers (Nebe, 2012). The intervention by the government is economic oriented while ignoring the complex and inherent dynamic social-cultural, biological and legal dynamics of the Kenyan youth. (Gribble, 2010).

Social problems have become more complex to social workers providing services to youths, as they face numerous challenges in carrying out interventions that aim at improving the life of the youths. According to Teater (2010), the interventions are usually based on social theories and models that provide helpful basis for designing interventions to bring out the desired outcomes. However, these theories and models provide little guidance on how to carry out practical intervention. Social workers working with the youth have realized the traditional approaches have become ineffective and obsolete to meet the contemporary needs of the dynamic youth population.

\subsection{Basic social work methods 1.1.1 Social Casework:}

Social case work consists of those processes which develop personality through adjustments consciously affected, individual by individual, between men and their social environment' with their problems (Alpa, 2014). This method basically involves a one-to-one relationship between a social worker and the client. It is the oldest and most commonly used method of social work. The individualized approach is used to mobilize the client's capacity and resources toward the solutions of his or her problem (Miley, 2016). The individual receives help by being encouraged to rely on his/her ability to solve the problem. Some of the principles, theories and techniques used in social casework originate in psychology and psychiatry. Individual caseworkers, whose beliefs stemmed from the moral model of treatment (Jackson, 2001), focused on the responsibilities of the individual and his or her character in the helping relationship. 
Case work has been cited as a method that improves (Cameron \& Buckley, 2013) a relationship which includes elements of emotional bonding and task consensus which has a beneficial impact on the person being assisted. However, the beneficial effect will be constrained by the person's capacity for relationship and level of insight. The evidence confirms that time is required for the relationship to become effective, and that case management outcomes can only be assessed once this relationship has been established this may delay the intervention as the situation of the client worsen (Cameron \& Buckley, 2013).

\subsubsection{Social Group Work:}

This method uses groups as a medium of action and intervention (Shulman, 2012). The overriding aim of this approach is to improve the functioning of group members through greater ability for establishing mature relationships, self-awareness and a sense of belonging (Toseland, 2005). It focuses on social reform and emphasizes such principles as social participation and learning through meaningful group interaction and communication. The main principles and techniques used in this approach are largely derived from group dynamics (Bellamy, Bledsoe, \& Traube, 2010). These include; Educational Groups, Therapy Groups, Psycho educational Groups, Task Groups, Support Groups, Self-Help Groups, and Community Organizing Groups.

This method has been cited to undermine confidentiality which is a major concern for some young people. Many do not understand the extent and limits of confidentiality and may make incorrect assumptions about how their personal information is handled (Cameron \& Buckley, 2013). This has made many youths not to open up for the therapy and even shy away from social work organized group secession (Otieno \& Okuku, 2017). While in practice, Group workers and caseworkers often experienced tense relationships. A great deal of misunderstanding existed concerning their roles in group work in particular (Malekoff, 2015).

This tension in the profession continues to exist to this day between those who advocate social change and transformation and those who view the profession more in terms of individual change. It may seem obvious, yet it is very easy for groups to shift and change over time, without members or leaders being clear about these changes. It is helpful for group leaders to be clear about the purpose of the group, which involves providing members with a sense of the purpose of each activity or section of an individual group session.

\subsubsection{Community Organization:}

Community organization is defined as a movement designed to promote better living for the whole community, with the active participation and if possible at the initiative of the community (Alpa, 2014). This approach concentrates on the improvement of the general welfare of the community as a whole. It is coordinated by a worker who, acting through groups of people, helps the community to consulate and implement social projects and programmes for the benefit of the entire community. The basic aim of community organization is to promote self-reliance and collective socio-economic development (Mackelprang \& Salsgiver, 2015).

The social work practitioners have applied these techniques and in situations they have realized challenges, they have identified innovative ways of addressing youth challenges. Therefore this study is set to disentangle the emerging and innovative social work techniques arising from afore mentioned social work methods.

\subsection{Statement of the Problem}

Modern day social work is practiced in a context of rapid changes in the social environment and social institutions. Practicing social work is now more complex, complicated, diverse and demanding than at any time in its history. Social workers providing services to the youth face numerous challenges in carrying out interventions that aim at improving the quality of their lives. There exists barriers that are embedded in political, economic, social, technological and organizational changes which are influencing and shaping the profession.. The interventions are usually based on social theories and models that provide helpful basis for designing interventions to bring out the desired outcomes. However, these theories and models provide little guidance on how to carry out practical intervention. It is evident that social workers working with the youth have realized that the traditional approaches have become ineffective and obsolete to meet the contemporary needs of the dynamic youth population. This has led to the development of innovative social work 
interventions that seek to achieve social transformation among the youth. This innovations which are being implemented by youth empowerment organizations are important not only to the social workers that utilize them and their clients but also for the upcoming professionals and institutions that provide services to the youth. Therefore this study is set to find out and explain the emerging social work techniques in youth empowerment programmes as well as their importance in social work practice. The overall objective of this study was to unravel the Emerging Social Work techniques in Youth Empowerment programs in Nairobi County.

\subsection{Method}

The literature on emerging social work techniques was searched on Google scholars, web "social work innovations," "social work techniques, "youth empowerment, importance of social work techniques, challenges in social work innovations. Article reference lists were also used the websites social work, government articles and international organization documentations such us UN were also searched. Selected articles synthesized the literature on the emerging Social Work techniques in youth empowerment programs. The search was limited to English articles and excluded dissertations. Researcher reviewed each abstract to eliminate articles that were not relevant. Selected articles were reviewed to explore the Emerging Social Work techniques in Youth Empowerment programs. Books and journals were also reviewed and analyzed using content analysis

\subsection{Theoretical framework}

\subsubsection{Diffusion of innovation model}

Innovation of diffusion was developed by Everett Rodgers in 1995, it explains how innovation is conceived and communicated to the population through persuasive means (Everett, 1995). Diffusion of Innovations seeks to explain how innovations are taken up in a population. An innovation is an idea, behaviour, or object that is perceived as new by its audience. Diffusion of Innovations offers three valuable insights into the process of social change (Everett, 1995). This process is significantly important for the development of new social work techniques and its adoption by other change agents.

The type of innovation-decision is related to an innovation's rate of adoption. Innovations requiring an individual-optional innovation decision are generally adopted more rapidly than when an innovation is adopted by an organization. The more persons involved in innovation. According to (Jürgen, Anna, Dmitri, \& Christoph, 2014) states that social innovations encompass new practices, concepts, policy instruments, new forms of cooperation and organization, methods, processes and regulations that are developed and/or adopted by citizens, customers, politicians. They further illustrate that in order to meet social demands and to resolve societal challenges in a better way than existing practices. Social workers need to practice models and methods that work.

Social workers must always understand theories in order to innovate a technique, or an intervention (Teater, 2010). The theoretical and conceptual approaches have in common micro and meso scale perspectives which make them appropriate to theoretically and empirically study social innovation. This provides a better understanding of the multiplicity of drivers and initiatives engaged in the process of invention, creation, imitation and adoption of technological and social innovation in comparing the existing intervention they state that system and structural theories should be modified to understand social practices (Jürgen, Anna, Dmitri, \& Christoph, 2014).

The latter can be found between routines and incalculability, (Dominelli, 2009) closeness and openness for change and make a possible view on their reconfiguration as a core element of social innovation. The theory is significant in explaining why social work has been slow to adopt technology limited resources, ethical and legal considerations, lack of training, and social work's historical reliance on face-to-face communications have fueled this lag (Everett, 1995). In some states social innovation is absent as practitioners culture and the older methods hinder emergence of social innovation. 


\subsection{Empirical Review}

\subsubsection{The emerging social work techniques in youth empowerment programmes}

Empowerment is a polemic word in social work profession. It is an indispensable term in the social work profession which defines social work as a practice. The goal of empowerment is facilitated by the process of concietization through which people in disadvantageous circumstances are helped to acquire a critical and reflexive consciousness (Mutuku, 2011). However, this requires a good approach and the correct interventions for unflinching empowerment.

Jennings (2005) asserts that youth empowerment are circumstances and factors which tend to enhance development of citizens especialy during their transition to adulthood. There are three level of youth empowerment these include individual, organizational and community empowerment (Morton and Montgomery, 2013). Mutuku (2011) cites Zimmerman and Warschausk (1998) who explained that, the individual level of empowerment entails psychological empowerment which comprised of the intrapersonal, interactional, and behavioral components. Social workers dealing with psychological empowerment offer wide range of programmes and interventions.

The Organizational level provides an opportunity to develop and influence policy decisions, or offer effective alternatives for service provision. At the community level, "empowerment may refer to collective action to improve the quality of life in a community and the connections among community organizations and agencies Social workers in their practice deals with youth at both level, this due to generic nature of social work as a profession. (Clemons, 2014)

According to Cameron and Buckley (2013) the youths are highly vulnerable and with limited support and often experienced a complex and dynamic process where the social workers needs to balance a range of considerations. Mackelprang and Salsgiver (2015) states that social workers use certain methods and techniques which are blurred or unacceptable in empowement interventions. In there arguments they questioned the type and nature of the complaints which social workers ought or should be dealing with, given the intractability and ambiguity that characterize empowerment programes or initiative.

Nandan, London and Bent-Goodley (2014) observe that social theory doesn't play an important role in social innovation research, he argue that possible contributions have to be explored. The scientific discussion on social innovation is polarized between an actor centered, individualistic, attitude orientated perspective on the one hand and a structuralistic perspective on the other hand. Social innovations are either attributed to individualistic acts, or considered a deterministic result of external context (Nandan, London, \& Bent-Goodley, 2014).

Teater (2010) tends to disagree with them stating that the new innovations always originate from theories' which are used to design a method, a technique and interventions. He argues that theories inform the social worker the type of method he/she should use with the client in a certain situation. The scholar supports his argument stating that because of this oversight, not only do practitioners run the risk of implementing interventions that are ineffective due a lack of cultural fit between the intervention and the targeted population (Teater, 2010). Through this experience there have emerged new different techniques which are now being embraced in youth empowerment programs. These new techniques are discussed below;

\subsubsection{Digital social work interventions}

Digital social work techniques have have become very common with the rapid growth of technology this methods involed the use of social media, and other digital plattform to carry out interventions. Accoding to (Cameron \& Buckley, 2013) Digital communication technologies play an integral role in the social inclusion of young people in our society. For many people 'Google' represents a first port of call for information on multiple and varied topics. Most services have developed websites with information and resources relevant to their target group. These websites can be an important source of information and a useful tool for engagement, as it is clear that many young people will be assessing the suitability of a service based on the information provided on the service's website.

However, lack of awareness among the youth health workforce of evidence-based approaches to using technologies to improve young people's mental health and wellbeing. This limits their capacity to use these services and demonstrates that education to address this knowledge gap is much needed; A lack of policies and procedures within individual organisations and the service system that support the safe and health- 
promoting use of technologies; and the absence of appropriate technological infrastructure within individual organisations and the service system (Bellamy, Bledsoe, \& Traube, 2010).

\subsubsection{Individual/ personalization}

This techniques focused on youth based assets or what the youth already have. This can include youth's talents such as, Artwork, murals, and photos, galleries etc. developed by young people can help create a space that is appealing, welcoming, and culturally responsive (Cameron \& Buckley, 2013). The interventions thrive well in psychological empowerment which include, skill development for economic income, mentorship which assist in self-awareness, (Mutuku, 2011). The Kenyan youths are rocked with litany of challenges which are embedded in their larger living conditions (Mohammed, 2008).

Studies have revealed that this social work intervention has assisted youths and their families in addressing the social, emotional and financial factors that have a significant impact on youth development and freeing them from chains of poverty (Otieno, 2017). This has been done along several programmes. However, these interventions have relied heavily on donors who sometimes withdraw leading to collapse of these golden interventions. Jürgen, Anna, Dmitri, \& Christoph (2014) assert that innovative ideas and techniques are needed by social workers to sustain the interventions. The scholars argue that it's hard for social workers to talk about new techniques in the social work practice.

\subsubsection{Bi-clients interventions}

This is a form of having an accountability partner intervention monitored by the social worker. The social worker identifies two clients who are very close to one another. They are then encouraged to help each other in therapeutic process .The Bi-client interventions is taking shape among youths living with HIV. The relational orientation among them is influenced by the warmth and empathy of the practitioner and the young person's level of confidence in the service and the worker, their receptiveness to empathy, and their own sociability (Cameron \& Buckley, 2013).

The process of working with highly vulnerable young people is not straightforward. It is often unpredictable, interspersed by various crises, emotionally up and down (for everyone, including workers), in an environment of resource scarcity. Practitioners need to both see the young person as a client in their own right but also consider their particular developmental needs (Alpa, 2014). This requires practitioners to be critically aware, proactive and sometimes assertive. In the absence of sufficient accountability partner's support, many practitioners are required to fulfill a protective role in the lives of their clients. The ethical challenges involved in working in this space and maintaining professional standards are substantial when using this techniques (Cameron \& Buckley, 2013). The strengths of young people need to be more appreciated. We often underestimate the capacities and resources of young people.

\subsubsection{Social work on site/institute}

Social work on site/insitu is a proactive engagement approach targeting young people especially street children, where interventions take place on the streets, social workers help the youths to organize themselves to facilitate therapy among themselves (Patel, Edwell, \& James, 2012). Effective engagement requires a responsive, adaptable and flexible approach which is mindful of the circumstances surrounding a young person's substance use. Flexibility may need to be in respect of place (going to where young people are at through outreach), time (hours of the day or night), type of strategy (through activities and mediums that young people want to participate in and engage through), form of communication (verbal, experiential, expressive, social media), or social context (individual, peer, family and community (Cameron \& Buckley, 2013)).

Kenya is one of the four countries burdened with HIV and AIDS an estimated 1.6 million people live with HIV (Otieno \& Okuku, 2017). Social work addresses social determinants of health among the youth. During their visits on site, social workers do the following; risk management, providing psychosocial assessment and follow-up to improve the youths drug adherence, self-management, and to reduce potential for conflicts, complaints and/or litigation, Program Development: providing leadership and participation in program planning, development and evaluation to ensure patient-centered goals are met (Irish Associaltion of Social Workers, 2011).

Social work role are generic, according to (Dominelli, 2009), social work professional intervention occurs in three ways, which include Maintenance- where social work deals with individual and families and policies; 
it also deal with interpersonal relationships, disaster management. "Therapeutic" which involves social work dealing with people with different disabilities; mental problem counseling services it also combine both maintenance and emancipators. The last intervention is described as Emancipator forms the core role of social work in the health care setting. According to, (Moriartyet al, 2015) social workers are uniquely skilled in accessing a wide range of practical and emotional support and services to meet individuals' needs and aspirations; in this way therapeutic services offered by social workers improve patient confident, by building capacity to cop up with complexities of health.

\subsection{The importance of emerging social work technique in youth empowerment programmes}

Clemons (2014) asserts that Professional social workers are required to develop and practice ongoing social work knowledge, values and skills in order to be competent social workers. The skills are agued to be developed from behavioral theories and other social theories which form a basis for social work practice (Teater, 2010). However, these theories have been criticized that they only provide guild lines to the practice or intervention. It has also been noted by (Clemons, 2014) that University students and social work practitioners face the challenge of taking an abstract concept, the "art" of social work as such, and combining it with evidence-based practice skills. This has seen many techniques fail.

Social work is a noble profession that has its root in social justice and empowerment of the most marginalized (Dominelli, 2009).The unflinching intervention can only be achieved through utilizations of the correct interventions, models, methods and skills which are grounded on social theories. However, social work professional have cultured the older methods as they tend to assume that these methods are culturally neutral and applies to all interventions in all geographical area. This assumptions has been cited to lack cultural fit between the intervention and the targeted population (Mackelprang \& Salsgiver, 2015). The new innovations of techniques drawn from practitioner's experiences can therefore be significant in addressing the void in youth intervention empowerment programmes (Jürgen, Anna, Dmitri, \& Christoph, 2014).

New innovations of social work techniques and methods are needed, to solve the dynamic of social problems. Nandan, London and Bent-Goodley (2014) challages in service provisions always provide opportunity for social innovations, which helps to break through the vicious cyle of monotonous methods of interventions which does not yield any fruits. The justifications of the emergence of a new paradigm in social work practice has been seen to be important in social work interventions and youth empowerment programme. The innovations have become a bases of promoting greater devotion and greater attention to social innovation as a mechanism of change residing at the micro and meso level (Jürgen, Anna, Dmitri, \& Christoph, 2014). The new techniques are also meant to address the shortcomings of older models of social change and of an economically and technologically focused innovation model which are becoming increasingly apparent when dealing with today's key social challenges. (Jürgen, Anna, Dmitri, \& Christoph, 2014).

New techniques have the potential to improve quality and delivery of social services, though risk taking is inherent in their implementation (Jürgen, Anna, Dmitri, \& Christoph, 2014) Innovation in the social sphere means accomplishing more with less, working together, leveraging resources, sharing data and creating models for change that are sustainable. Social innovation incorporates both idea generation and social sustainable outcome. Innovative programs are "a new or different way to address a societal problem or pursue a charitable mission that is more effective, efficient, sustainable, or just than prevailing approaches. A goal of social innovation is to meet social needs while the innovation is developed and diffused through organizations (Jürgen, Anna, Dmitri, \& Christoph, 2014).

\subsection{The common techniques of social work intervention in youth empowerment programmes}

A study conducted by Otieno and Okuku (2017) on social cultural factors and HIV in Homabay Kenya revealed that fear arousal models are no longer working in HIV prevention among the youths. They observes that. Despite, the availability of many agency working in the region applying several HIV prevention techniques HIV was still prevalence in the area. The study further revealed that, numerous strategies like of psychosocial interventions, counselling, and awareness creation as well as seminars and workshops did not 
have much impact on the youth sexual behaviour. In fact the scholar's state that they only increase knowledge but does not change the behaviour of the youths (Otieno \& Okuku, 2017). The scholars recommend on culturally integrated techniques in HIV prevention interventions.

Several models and techniques have proved to be futile in addressing social problems due to lack of proper innovations and complexity in current social problems in the society (Grace Christ, 2016). While advocating for culturally grounded methods of social work practice (Mackelprang \& Salsgiver, 2015) states that professional social work is a western invention, but often it is taught as if its methods of interventions are culturally neutral. he note that many profesional are not aware of cultural diversity. He ilustrates that Oneon-one interventions present challenges because the social worker often has more power than the client does and when the method fails the social workers tend to blame the client (Mackelprang \& Salsgiver, 2015).

Mackelprang and Salsgiver (2015) augues that one on one methods tend to disregard the unique contributions and needs of different ethnic communities. Instead, they aploud family interventions, group work, and community interventions, which are naturally conducive to horizontal relationships and client participation and empowerment. (Maritta, Olga, Valentina, \& Eveliina, 2013) support this augument, they state that Social support is part of people's everyday life when reconstructing their well-being. Social support comes with the ideas of helping and sementing solidarity among the clients. These methods have been used among the youths abusing drugs, and proved to be effective in many ways. However new innovations is still required for better service delivery (Mackelprang \& Salsgiver, 2015).

Professionals working with young people have developed different youth empowerment models such which has proved to be effective include. The youth development and empowerment Approach (YDEA), by Kim, Crutchfield, Williams, and Hepler. It recognizes that young people as assets and resources that should be utilized in community and social affairs, emphasizes participation, where youth have opportunities to learn. (Mutuku, 2011), other models include Adolescent Empowerment Model (AEM), which emphasizes the importance of providing meaningful roles for adolescents. They believe that such roles can provide stability for adolescents during a time of identity crisis and formation, and combat a lack of purpose experienced by many young people. (Mutuku, 2011), the models deals with psychological empowerment of the young people.

\subsection{Impediments in utilizing the emerging social work techniques in empowerment programs}

The non-recognition of social workers may explain why so many social problems are taken to the courts, district commissioners, priests and witchdoctors. Needless to say, the non-recognition of social work tends to discourage and demoralize practitioners as well as those who might be interested in pursuing careers in this field (Bellamy, Bledsoe, \& Traube, 2010). Lack of professionally-trained social workers is a major constraint on social work in Africa. The absence of knowledge about how to best access, critically evaluate, and translate evidence for appropriate use with their clients (Bellamy, Bledsoe, \& Traube, 2010) is a greater challenge to our social workers.

The lack of fit theme includes the reasons why practitioners feel that available evidence or research is not often helpful. Some feel that the emerging techniques are cookbook approaches that are too broad. Research findings are slow to develop, and once findings are presented, it may take considerable time before policies are aligned with new knowledge (Alpa, 2014). The culture of knowledge transmission within social work has been historically unsupportive of the use of research evidence in practice. The chasm between research and practice is further widened by practitioners' inability to contribute to the formal body of social work knowledge that they are expected to employ this is also complemented by natural resistance to innovation (Bellamy, Bledsoe, \& Traube, 2010).

Social workers are one of the most overworked, underpaid, under-recognized and distressed professionals. The reward system for social workers is ineffective to motivate them to innovate new ways of intervening while addressing youth challenges. Most social work programmes have based on models and theories that have been practical in Europe and America but do not consider the cultural context in Africa thus leave much to be desired, especially in terms of their relevance to the African situation. 
The curriculum and other vital components of instruction remain largely conservative and underdeveloped. It is common knowledge that many of the social workers teaching in African universities were trained using curriculum prepared in Europe and North America. Attempts to reverse this Eurocentric bias in social work training have not been successful (European Commission, 2015). Knowledge barriers are those that speak to the general lack of awareness of available emerging techniques and the difficulty in processing or understanding research findings when they are identified (Bellamy, Bledsoe, \& Traube, 2010).

\section{Conclusion}

Extra-ordinary situations require extra-ordinary measures and techniques. The fact that the operating environment in Africa and specifically Kenya is changing, there is a high need to also innovate new techniques to be used to address social challenges affecting the youth. Different techniques for social work intervention among the youth are based on claimed rather than demonstrated effectiveness in assisting youths in empowerment. The emerging techniques have been to ignore due to contradiction between claims and reality and to censure this information from the academic and practice community. Social workers are integral participants in the process of shaping and delivering support and needed interventions for clients and communities.

This study recommends the following;

1. Documentation of emerging social work interventions in youth empowerment and development programs,

2. Sharing of information and utilization on the new techniques and methodologies among social workers working with the youth. Training of Social workers on how to utilize social research to enhance their capacity in technique development,

3. Organizing regular seminars and workshops where social workers can share and learn more about the new and emerging social work interventions.

4. Curriculum review should urgently be initiated to accommodate the African social cultural dimensions of social work service.

\section{References}

[1] Agenda, Y. (2013). Youth Problem Youth Solution: 2013-2017 Priorities . Nairobi: Youth Agenda.

[2] Alpa, P. (2014, March). Methods of Social Work and Its Role in Understanding Team Climate and Team Effectiveness for Organizational Development. Journal of Sociology and Social Work, 2, 303318.

[3] Bellamy, L. J., Bledsoe, E. ,., \& Traube, E. D. (2010). The Current State of Evidence-Based Practice in Social Work: A Review of the Literature and Qualitative Analysis of Expert Interviews. National Institute of Health Public Access.

[4] Broadhurst, K. (2016). Innovation in social work research. Qualitative Social Work, 3-10.

[5] Cameron, P. C., \& Buckley, J. (2013). Youth alcohol and drug practice guide 3: Practice strategies and interventions. Brisbane: Dovetail.

[6] Clemons, J. W. (2014). Client System Assement Tools For Social Work Practice. NACSW Convention (pp. 1-14). Maryland: North American Association of Christians in Social Work.

[7] Dominelli, L. (2009). Introducing social work, short introduction (3rd ed.). USA: polity press.

[8] European Commission. (2015). The contribution of youth work to address the challenges young people are facing, in particular the transition from education to employment. United Kingdom: European Commission.

[9] Everett, M. R. (1995). DIFFUSION OF INNOVATION. New York: THE FREE PRESS.

[10] Grace Christ, S. D. (2016). the role of social work in managing chronic illness care.

[11] Gribble, J. (2010). Investing in Youth for National Development. USAID. Washington, DC: Population Refference Burea.

[12] Irish Associaltion of Social Workers. (2011). THE ROLE OF SOCIAL WORK IN PRIMARY CARE IN IRELAND. Dublin: National Social Work Organisation of Ireland Limited.

[13] James, L., Melanie, G., Erika, S., Jooyoung, K., \& Carrie, J. (2015). SOCIAL ISOLATION PRESENTS A GRAND CHALLENGE FOR SOCIAL WORK. USA: American Academy of Social Work \& Social Welfare 
[14] Jürgen, H., Anna, B., Dmitri, D., \& Christoph, K. (2014). THEORETICAL APPROACHES TO SOCIAL INNOVATION A CRITICAL LITERATURE REVIEW. In H. Jürgen, B. Anna, D. Dmitri, $\&$ K. Christoph, 'Social Innovation: Driving Force of Social Change (pp. 1-160). Dortmund, Sozialforschungsstelle.: European Unionlls Seventh Framework Programme for research.

[15] KENYA NATIONAL YOUTH POLICY . (2007). SESSIONAL PAPER NO. 3. Nairobi: Ministry of Youth Affairs.Mackelprang, W. R., \& Salsgiver, O. R. (2015). Disability: A Diversity Model Approach in Human Service Practice. Washington DC: Lyceum Books.

[16] Maritta, T., Olga, B., Valentina, S., \& Eveliina, H. (2013). Empowering Social Work: Research \& Practice. Kotka: University of Helsinki.

[17] Mutuku, C. M. (2011, August). YOUTH PERSPECTIVES ON THEIR EMPOWERMENT IN SUBSAHARAN AFRICA: THE CASE OF KENYA. A dissertation submitted to Kent State University in partial fulfillment of the requirements for the degree of Doctor of Philosophy. Kenta: Unpublished.

[18] Mwiti, K. G. (2006). Child Abuse: Detection, Prevention and Counselling. Nairobi: Evangel Publishing House.

[19] Nandan, M., London, M., \& Bent-Goodley, T. (2014, November). Social Workers as Social Change Agents: Social Innovation, Social Intrapreneurship, and Social Entrepreneurship. Facaulty Publications, pp. 1-36.

[20] Otieno, E. J., \& Okuku, M. T. (2017). Social cultural factors contributing to the spread of HIV and AIDS in Homabay County, Kenya, . In A. N. Maurice, Beyond Agency, Voice and Space in Africa's Development (pp. 135-146). Nairobi: Centre for Democracy, Research and Development.

[21] Patel, L., Edwell, K., \& James, M. (2012). Indigenous Welfare and Community-Based Social Development: A Diversity Model Approach in Human Service Practice. Journal of Community Practice, 12-31.

[22] Silvia, S.-B. (2009). Social Work as a Discipline and Profession. In V. Leskošek, theories and methods of social work: exploring diffrent perspective (pp. 1-30). Ljubljana: Faculty of Social Work, University of Ljubljana.

[23] Teater, B. (2010). An Introduction to applying social work theories and methods. Egland: open university press.Theories and Methods of Social Work: Exploring Different Perspectives. (n.d.).

[24] Yumi, O., \& Kiyoshi, K. (2014). A New Intervention Skills and Measurement Method for Clinical Social Work Practice. Japanese Journal of Social Welfare, 11-22 